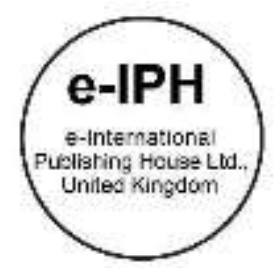

\title{
Student's Learning Style and Achievement after being Taught Contextually
}

\author{
Zulkarnain Md Amin, Nafisah Kamariah Md Kamaruddin, \\ Norziha Che Him , Ahmad Badruridzwanullah Zun \\ Universiti Tun Hussein Onn Malaysia, Parit Raja, Batu Pahat 86400, Johor
}

Email of All Authors: zulkarn@uthm.edu.my, nafisah@uthm.edu.my, norziha@uthm.edu.my, ahmadbadrur87@outlook.com Tel of 1st Author:+6 0133635634

\begin{abstract}
Contextual learning combines examples taken from everyday experience. The purpose of this research is to identify whether learning contextually will improve students' achievement. A quasi-experimental design used. The engineering students were divided into contextual and non-contextual groups. The Neuro-Linguistics Programming (NLP) VAKD Preferred Representational Systems Test shows, majority of both groups use auditory digital learning styles. There is a significant difference at a significance level of .05, in the achievement test where the contextual groups performed better. The majority of the students in both groups are auditory digital learning styles, learning statistics contextually is an effective method for engineering students.
\end{abstract}

Keywords: NLP VAKD, learning styles, statistics, contextual

eISSN: 2398-4287@ 2021. The Authors. Published for AMER ABRA cE-Bs by e-International Publishing House, Ltd., UK. This is an open access article under the CC BYNC-ND license (http://creativecommons.org/licenses/by-nc-nd/4.0/). Peer-review under responsibility of AMER (Association of Malaysian Environment-Behaviour Researchers), ABRA (Association of Behavioural Researchers on Asians/Africans/Arabians) and CE-Bs (Centre for Environment-Behaviour Studies), Faculty of Architecture, Planning \& Surveying, Universiti Teknologi MARA, Malaysia.

DOI: https://doi.org/10.21834/ebpj.v6iSI4.2908

\subsection{Introduction}

Students do not have the same learning styles because they have from different backgrounds. Even though researchers define the terms learning style differently, most of them focus on the preferences when accepting information-learning styles influence a learner's information processing and cognition in terms of attention, perception and thinking and learning behaviour (Shukri et al., 2013).

Research on the preferred learning style of engineering students has been done. The findings are different as there are many different types of learning style questionnaires. According to Driscoll \& Garcia (2000), results obtained from the profiles of freshmen and junior-level Chemical Engineering students using VARK indicate that students preferred kinaesthetic (hands-on) mode, either by itself or in combination with other learning styles (multimodal). In the study done by Tulsi, Poonia and Anu (2016), from the sample of 175 students, there exist differences in learning styles of civil, electrical, electronics, communication and mechanical engineering students, and also of the computer science and engineering post-graduate students. The majority of the students of various branches except mechanical engineering prefer active, sensing, visual and sequential learning styles. Sahatcija, Ora, and Ferhataj (2017) used the Gregorc (2017) classification, which consists of four categories: concrete-sequential, concrete random, abstract-sequential, abstract-random, and they found out that most Albanian university students use the first thinking style, namely concrete-sequential thinking style. According to Ictenbas \& Eryilmaz (2011), to meet the needs of those students in different ways, instructors must design their courses differently. In their research using the Turkish version of the VARK questionnaire, from 20 engineering students, approximately $25 \%$ of students prefer many learning styles within the classroom. This is followed by the kinaesthetic style, which

eISSN: 2398-4287C 2021. The Authors. Published for AMER ABRA cE-Bs by e-International Publishing House, Ltd., UK. This is an open access article under the CC BYNC-ND license (http://creativecommons.org/licenses/by-nc-nd/4.0/). Peer-review under responsibility of AMER (Association of Malaysian Environment-Behaviour Researchers), ABRA (Association of Behavioural Researchers on Asians/Africans/Arabians) and cE-Bs (Centre for Environment-Behaviour Studies), Faculty of Architecture, Planning \& Surveying, Universiti Teknologi MARA, Malaysia.

DOI: https://doi.org/10.21834/ebpj.v6iSI4.2908 
requires real-life practice to enhance knowledge of the subject. This study has also shown that engineering students prefer applied instruction to improve their analytical and problem-solving skills.

Gaikwad (2017) said that critical question is ponder upon as the learning style of the students have a big impact on the way they perceive and learn. She said that by the application of different learning styles to teach various courses by educators, the learning could be improved. This is because, from her research using the survey conducted by Felder Solomon learning index, most of the engineering students are active, intuitive, visual and sequential learners, while most of the engineering-pedagogical styles tend to emphasize the opposite methods. In making these students motivated and interested in their studies, she added that faculties should take care to use appropriate strategies in generating employable engineers.

The thinking style that was used in this research is from the Neuro-Linguistics Programming (NLP) Preferred Representational Systems Test. NLP or Neuro-Linguistic Programming by Richard Bandler and John Grindler identify four primary modalities for learning: Auditory, Auditory, Digital, Visual and Kinaesthetic. According to Losier (2009) and Mahoney (2007), Auditory people learn best by listening and often do not take notes; people who are Auditory Digital learn best by working things out in their mind, Visual people learn best by creating visual pictures in their mind and Kinaesthetic people, learn best through doing.

This research focused on students' achievement when they were taught using contextual approaches in learning statistics. It was intended to ascertain how this approach would affect learning transfer between the class lectures to real-life situation problems. In contextual teaching and learning, students discover meaningful relationships between abstract ideas and practical applications in the context of the real world; concepts are internalized through the process of discovering, reinforcing, and relating. They want the answer to the question "Why do I have to learn this?" (CORD, 1999, 2016). The contextual lesson proposed by CORD (1999) is done so that it contains numerous examples that clarify concepts and provide students models for solving applied real-world problems; it provides students with an interesting and relevant way of translating mathematics from an abstract, theoretical approach to concrete. In this research, students learn statistics contextually by giving real-world examples, solving real-world problems, and showing real-world simulation videos on statistics.

\subsection{Methodology}

This study used a Quasi-experimental design. Two hundred sixty-eight diploma students from six classes which consisted of two classes of civil engineering students, two classes of electrical engineering students and two classes of mechanical engineering students. For this research, these six classes were divided into two main groups: control group or non-contextual group (NCTL) and experiment or contextual group (CTL). Six combinations of these classes were constructed, and a t-test was done to find out whether there was any significant difference in the combination of the classes. There were two classes for civil engineering students. If Class 1 Civil was selected in the non-contextual group, then Class 2 Civil would be in the contextual group. The same thing for Class 3 Electrical with Class 4 Electrical and Class 5 Mechanical with Class 6 Mechanical. From these selections, each group would have all three fields so that the field of studies would be a control variable. The six combinations of classes are shown in Table 1.

Table 1. Summary of the combination of the class

\begin{tabular}{|l|l|l|l|l|l|l|}
\hline $\begin{array}{l}\text { Class } \\
\text { Combination }\end{array}$ & \multicolumn{1}{|l|}{ Civil } & \multicolumn{2}{l|}{ Electrical } & \multicolumn{2}{l|}{ Mechanical } \\
\cline { 2 - 7 } $\begin{array}{l}\text { Combination 1: } \\
\text { CNNCCN }\end{array}$ & CTL & NCTL & NCTL & CTL & CTL & NCTL \\
\hline $\begin{array}{l}\text { Combination 2: } \\
\text { NCCNNC }\end{array}$ & NCTL & CTL & CTL & NCTL & NCTL & CTL \\
\hline $\begin{array}{l}\text { Combination 3: } \\
\text { CNNCNC }\end{array}$ & CTL & NCTL & NCTL & CTL & NCTL & CTL \\
\hline $\begin{array}{l}\text { Combination 4: } \\
\text { NCNCNC }\end{array}$ & NCTL & CTL & NCTL & CTL & NCTL & CTL \\
\hline $\begin{array}{l}\text { Combination 5: } \\
\text { CNCNNC }\end{array}$ & CTL & NCTL & CTL & NCTL & NCTL & CTL \\
\hline $\begin{array}{l}\text { Combination 6: } \\
\text { NCNCCN }\end{array}$ & NCTL & CTL & NCTL & CTL & CTL & NCTL \\
\hline
\end{tabular}

Then t-test was done to find out whether there was any significant difference between the two groups: non-contextual and contextual groups of the combination of the classes. There was significant difference between the two groups for combination $1(P=.00)$, combination $2(P=.00)$, combination $3(P=.02)$ and combination $4(P=.01)$ at a significance level of .05 as shown in Table 3.8 . However, there was no significant difference between the two groups for combination $5(P=.22)$ and combination $6(P=.22)$ at a significance level of .05 as shown in Table 3.9. Since there is a significant difference between Class 1 with a mean of 15.80 and Class 2 with a mean of 12.29 , Class 2 was chosen to be in the Contextual (CTL) group. This was to study whether a contextual approach can improve students' understanding of statistics. Thus, the combination that was chosen is Combination 6.

Table 2. Significant Difference between the Non-contextual and Contextual

\begin{tabular}{llllllll}
\hline Combination & $\begin{array}{l}\text { Combination 1: } \\
\text { CNNCCN }\end{array}$ & $\begin{array}{l}\text { Combination 2: } \\
\text { NCCNNC }\end{array}$ & $\begin{array}{l}\text { Combination 3: } \\
\text { CNNCNC }\end{array}$ & $\begin{array}{l}\text { Combination 4: } \\
\text { NCNCNC }\end{array}$ & $\begin{array}{l}\text { Combination } \\
\text { CNCNNC }\end{array}$ & $\begin{array}{l}\text { Combination 6: } \\
\text { NCNCCN }\end{array}$ \\
\hline$p$ & 0.000 & 0.000 & 0.018 & 0.008 & 0.224 & 0.224
\end{tabular}




\begin{tabular}{|c|c|c|c|c|c|c|c|c|c|c|c|}
\hline \multicolumn{3}{|r|}{ Significant } & Yes & Yes & No & No & & & & & signiticant \\
\hline
\end{tabular}

All students answered the NLP Preferred Representational Systems Test to determine their learning style. Then the contextual group was taught statistics contextually using Contextual Statistics Modules, while the non-contextual group was taught statistics noncontextually using non-contextual Statistics Modules. After the researcher finished teaching, the contextual video or non-contextual video, based on their groups, were shown to them. The video is in English; however, during the video presentation, the researcher explains both in English and Malay. While showing the video to the students, the researcher explained or repeated the main points of the videos to the students. Then the students were given an achievement test. There were six questions in the test. The first two questions were problem-solving non-contextual questions; the next two questions were problem-solving contextual questions. As for the last two questions, both tests ask about the application of real-life events, which were normal or non-normal distribution.

\subsection{Findings and Discussion}

From the Neuro-Linguistics Programming (NLP) Preferred Representational Systems Test, Table 3 shows the distribution learning styles of the students in the Non-contextual group and the Contextual group. Thus, from these tables, the majority of the students for both groups had auditory digital learning styles, with 57 students in the non-contextual group and 59 students in the non-contextual group.

Table 3 The Distribution of the Learning styles for the Non-contextual Group

\begin{tabular}{lllllll}
\hline Learning Style & Visual & Auditory & Kinaesthetic & $\begin{array}{l}\text { Auditory } \\
\text { Digital }\end{array}$ & Unknown & Total \\
\hline Non-contextual & 18 & 18 & 41 & 57 & 2 & 141 \\
Contextual & 20 & 18 & 28 & 59 & 7 & 127 \\
\hline Total & 38 & 36 & 69 & 116 & 9 & 168 \\
\hline
\end{tabular}

Two-way ANOVA has been analyzed to investigate whether there is any significant difference in the non-contextual questions in the test between the two groups. Table 4 represent the variables in this test.

\begin{tabular}{llllll}
\multicolumn{6}{l}{ Table 4 two-way ANOVA analyses for Problem Solving Non-contextual Questions } \\
\hline Source & $\begin{array}{l}\text { Type II Sum } \\
\text { of Squares }\end{array}$ & df & Mean & S & $\begin{array}{l}\text { p- } \\
\text { value }\end{array}$ \\
& $140.615^{*}$ & 2 & 70.308 & 1.952 & 0.144 \\
Corrected Model & 50569.141 & 1 & 50569.141 & 1403.90 & 0.000 \\
Intercept & 120.731 & 1 & 120.731 & 4 & 0.068 \\
non-contextual_contextual & 9545.396 & 265 & 36.020 & 3.352 & \\
Error & 60135.000 & 268 & & & \\
Total & 9689.011 & 267 & & & \\
Corrected Total & \multicolumn{5}{l}{} \\
\hline a. R squared $=.015$ (Adjusted R Squared $=0.007$ ) Total \\
\hline
\end{tabular}

From Table 4, there is no significant difference in the problem solving non-contextual questions from the Post Test at a significance level of $.05(P=0.07)$.

Two-way ANOVA has been analyzed to investigate whether there is any significant difference in the problem solving contextual questions in the test between the two groups. Table 5 represent the variables in this test.

\begin{tabular}{|c|c|c|c|c|c|}
\hline Source & $\begin{array}{l}\text { Type II Sum } \\
\text { of Squares }\end{array}$ & $\mathrm{df}$ & $\begin{array}{l}\text { Mean } \\
\text { Square }\end{array}$ & $\mathrm{F}$ & $\begin{array}{l}\mathrm{p}- \\
\text { value }\end{array}$ \\
\hline Corrected Model & $241.867 a$ & 2 & 120.933 & 3.252 & 0.040 \\
\hline Intercept & 38226.668 & 1 & 38226.668 & 1028.01 & 0.000 \\
\hline non-contextual_contextual & 234.643 & 1 & 234.643 & 7 & 0.013 \\
\hline Error & 9853.984 & 265 & 37.185 & 6.310 & \\
\hline Total & 48114.000 & 268 & & & \\
\hline Corrected Total & 10095.851 & 267 & & & \\
\hline
\end{tabular}

There is a significant difference in the problem solving contextual question from the Post Test at a significance level of $.05(P=$ 0.013). The contextual group perform better, as shown in Table 6 with a mean of 12.90 and a standard deviation of 5.91, compared to the Non-contextual group, with a mean of 11.02 and a standard deviation of 6.24 .

Table 6 The Mean and Standard Deviation for Problem Solving Contextual Questions

\begin{tabular}{llll}
\hline Test & Mean & Std Deviation & $\mathrm{N}$ \\
\hline Non-contextual & 11.02 & 6.24 & 141 \\
Contextual & 12.90 & 5.91 & 127 \\
\hline Total & 11.91 & 6.15 & 268 \\
\hline
\end{tabular}


Two-way ANOVA has been analyzed to investigate whether there is any significant difference in the application of statistics questions in the test between the two groups. Table 7 represent the variables in this test.

Table 7 two-way ANOVA analyses for application of statistics questions

\begin{tabular}{llllll}
\hline Source & $\begin{array}{l}\text { Type II Sum } \\
\text { of Squares }\end{array}$ & df & $\begin{array}{l}\text { Mean } \\
\text { Square }\end{array}$ & F & $\begin{array}{l}\text { p- } \\
\text { value }\end{array}$ \\
\hline Corrected Model & $1446.337^{*}$ & 2 & 723.169 & 179.141 & 0.040 \\
Intercept & 4169.705 & 1 & 4169.705 & 1032.90 & 0.000 \\
non-contextual_contextual & 1445.128 & 1 & 1445.128 & 8 & 0.000 \\
Error & 1069.767 & 265 & 4.037 & 357.983 & \\
Total & 6444.000 & 268 & & & \\
Corrected Total & 2516.104 & 267 & & & \\
\hline a. R squared $=.015$ (Adjusted R Squared $=0.007$ )Total \\
\hline
\end{tabular}

There is a significant difference in the contextual question from the Post Test at a significance level of $.05(P=0.000)$. The contextual group perform better, as shown in Table 8, with a mean of 6.28 and a standard deviation of 2.21, compared to the Non-contextual group, with a mean of 1.62 and a standard deviation of 1.80 .

Table 8 The Mean and Standard Deviation for Questions on Application of statistics

\begin{tabular}{lccc}
\hline Test & Mean & Std Deviation & $\mathrm{N}$ \\
\hline Non-contextual & 1.62 & 1.80 & 141 \\
Contextual & 6.28 & 2.21 & 127 \\
\hline Total & 3.83 & 3.07 & 268 \\
\hline
\end{tabular}

For both groups, there is no significant correlation between the learning styles (VAKD) and the achievement scores, as shown in Table 8 for the Contextual Group and in Table 9 for the Non-contextual Group.

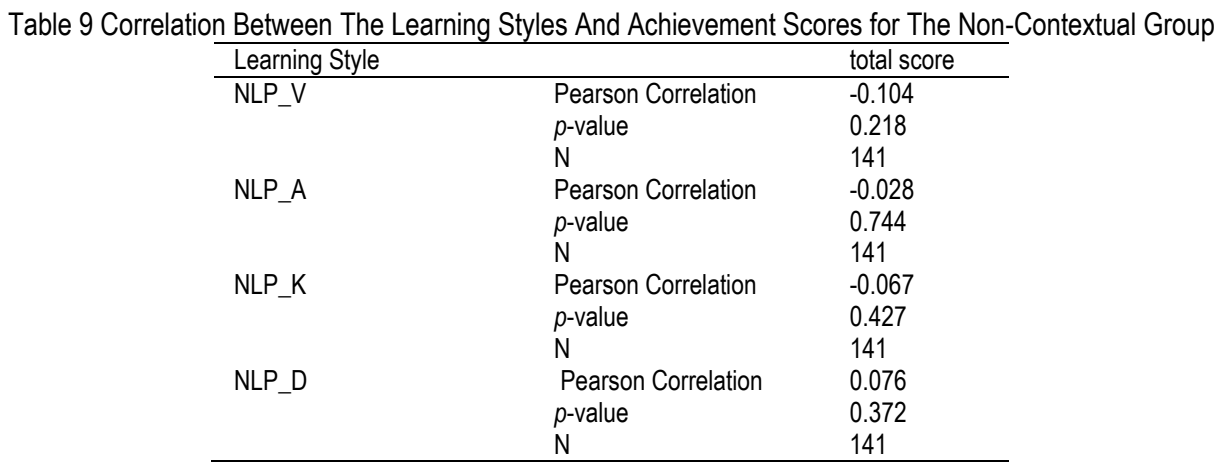

From Pearson correlation, all the learning styles do not show any significant correlation with the achievement score for the noncontextual group, as shown in Table 10.

Table 10 Correlation Between The Learning Styles And Achievement Scores for The Contextual Group

\begin{tabular}{lll}
\hline Learning Style & & total score \\
\hline NLP_V & Pearson Correlation & 0.072 \\
& $p$-value & 0.423 \\
& N & 127 \\
NLP_A & Pearson Correlation & 0.035 \\
& $p$-value & 0.699 \\
NLP_K & N & 127 \\
& Pearson Correlation & 0.023 \\
& $p$-value & 0.800 \\
NLP_D & N & 127 \\
& Pearson Correlation & 0.04 \\
& $p$-value & 0.964 \\
& N & 127 \\
\hline
\end{tabular}

From Pearson correlation, all the learning styles do not show any significant correlation with the achievement score for the contextual group.

\subsection{Conclusion}

The educators must know the learning style of their students. According to Richard M. Felder and Linda Silverman, it was found out that the mismatches between the methods of teaching and the student learning styles lead to poor student performance, professorial frustration, and a loss to society of many potentially excellent engineers (Felder, 2002). Even though researchers define the terms 
learning style differently, most of them focus on the preferences when accepting information. For example, Gokalp (2013) said that learning styles are not concerned with "what" learners learn, but rather "how" they prefer to learn, which is an important factor for students' academic achievement and attitudes.

Students taking engineering courses must be good at logical and critical thinking. It is important, as they have to make clear and rational decisions. These decisions need a process thought that is not only structured but also very important a logical. From this research, as the predicted majority of the students are auditory digital. These students memorize by steps and sequences process information rationally and logically (Losier, 2009). Therefore in this research, as expected, the majority of the students use Auditory Digital learning style instead of saying something "looks good", "sounds right", "feels nice", "tastes good", or "has the smell of success", a person with a preference for auditory digital may say, "this makes sense", "is logical" or "the specifications are correct" (Ellerton, 2013). This finding is similar to the research done by Tulsi et al. (2016), where engineering students prefer active and sequential learning styles. Sequential learning style must follow a logical style. For example, electrical engineering students must design basic components for sequential logic circuits. This finding is also similar to the research by Gaikwad (2017), where most of the engineering students are active, intuitive, visual and sequential learners. In addition, research by Ictenbas and Eryilmaz (2011), using the Turkish version of the VARK questionnaire, shown that engineering students prefer applied instruction to improve their analytical and problem-solving skills. However, results obtained from the research done by Driscoll et al., (2000) for a class of freshmen and junior-level Chemical Engineering students, using VARK, indicate that students preferred kinaesthetic (hands-on) mode, either by itself or in combination with other learning styles (multimodal).

In learning contextually, students learn how to relate what they learn in class to the real world. Students discover meaningful relationships between abstract ideas and practical applications in the context of the real world. From the contextual learning method, concepts are internalized through the process of discovering, reinforcing, and relating. This study shows that majority of the students learning style is auditory Digital, where these students learn by working things out in their mind and memorizing by steps and sequences process information rationally and logically. However, students usually were taught mechanistically where they use the formula without understanding the logic behind it. They just repeat what was learn and do not understand the concept of the topics. They have difficulty in relating what they learn in class to real-life questions, as they were not able to apply the concept of Normal Distribution in the real world. In addition, they were not taught to solve real-life questions, as they were unable to answer the questions. Based on the literature review, students try to find meaning in what they learn so that they can relate between abstract ideas and practical applications. From this study, students taught in the contextual method performed better than the non-contextual group. Thus, this method of teaching is suitable for students who have auditory digital learning styles.

\section{References}

CORD (1999). Teaching Mathematics Contextually: The Cornerstone of Tech Prep. Texas: CORD Communication, Inc.

CORD (2016) Overview of Contextual Teaching and Learning. Overview of Contextual Teaching and Learning.

Driscoll, S. A. and Garcia, C. E. (2000). Preferred Learning Styles for Engineering Students. Asee Peer. 5.504.1 - 5.504.10.

Dunn and Burke (2005). The Learning Style: The Clue To you.

Ellerton, R. (2013). NLP and Personal Growth Thoughts: A Series of Articles by Roger Ellerton PhD, CMC Volume 2. Renewal Technologist Inc.

Gokalp, M. (2013). The Effect of Students' Learning Styles on Their Academic Success. Creative Education 2013. Vol.4, No.10, 627-632Gold, S. A (2001). Constructivist Approach to Online Training for Online Teachers. Volume 5, Issue 1.

Ictenbas, B. D. and Eryilmaz, H. (2011).Determining Learning Styles of Engineering Students to Improve the Design of a Service Course. Procedia - Social and Behavioral Sciences 28, p 342

Lever-Duffy, J., McDonald, J. B. and Mizell, A. P. (2005). Teaching and Learning with Technology. Boston, MA: Allyn Bacon.

Losier, M. J. (2009). Law of Connection: NLP Communication Styles. Wellness Central. New York

Mahoney, T. (2007). Using NLP to Improve Communication, Learning \& Behaviour. Crown House Publisher Ltd

Sahatcija, R., Ora, A. and Ferhataj, A. (2017). The Impact of the Thinking Style on Teaching Methods and Academic Achievement. European Scientific Journal. Edition Vol.13, No.34.

Shukri, I, Zainab, R. and Rana, M. H. (2013).Learning Styles of Postgraduate and Undergraduate Medical Students. Journal of the College of Physicians and Surgeons Pakistan 2013, Vol. 23 (1): 25-30.

Tulsa, P. K., Poonia, M. P. and Anu, P. (2016). Learning Styles of Engineering Students. Journal of Engineering Education Transformations. Volume 30, No. 2. 